\title{
Sabina Spielrein, la primera mujer que enriqueció la teoría psicoanalítica
}

\begin{abstract}
RESUMEN: Sabina Spielrein produjo un impacto en la doctrina psicoanalítica a través de una interesante teoría de la represión que ponía en primer plano la tendencia a la destructividad que subyace en el ser humano, que Freud estimó como un antecedente de la pulsión de muerte. Además fue una fuente de inspiración para algunas de las ideas de Jung, como las de ánima y sombra, y para las teorías lingüísticas de Piaget.
\end{abstract}

PALABRAS CLAVES: Represión, pulsión de muerte, Freud, Jung, Piaget.

\section{Introducción}

La primera referencia a la presencia de mujeres en los grupos psicoanalíticos aparece en el I Congreso Internacional de Psicoanálisis celebrado el 27 de abril de 1908 en el hotel Bristol de Salzburgo. Allí estaba una doctora de Zúrich llamada Sophie Erismann, esposa de un conocido internista, así como Frieda Gross, de soltera Schloffer, mujer de Otto Gross (1877-1920), que había acudido para vigilarlo ya que su comportamiento suponía en muchas ocasiones un problema. Sophie desapareció del movimiento psicoanalítico tras el II Congreso Internacional de Psicoanálisis celebrado en Nuremberg en 1910, sin que dejara aportaciones de interés en la literatura especializada y Frieda también pasó pronto al anonimato. En las Actas de

\begin{abstract}
Sabina Spielrein had a great impact on psychoanalytic doctrine with an interesting repression theory that outstanded the role of destructiveness impulse that underlies within the human being, what Freud stimated as a antecedent of death's drive. Furthermore, she was a source of inspiration for some Jung's ideas, like anima and shadow, as well as for Piaget's linguistic theories.
\end{abstract}

KEY WORDS: Repression, Death's drive, Freud, Jung, Piaget.

las reuniones de los miércoles que inicialmente se celebraban en la consulta de Freud, consta que el 6 de abril de 1910 Paul Federn presentó como candidata a miembro de la Asociación Psicoanalítica a la doctora Margarethe Hilferding (1871-1942), propuesta que fue aceptada el día 27 del citado mes de abril con tres votos en contra. Margarethe (de soltera Honigsberg) había nacido en Viena, donde se doctoró en medicina, era de ideología social-demócrata y seguidora de Adler, por lo que abandonó el grupo freudiano cuando aquél formó su asociación independiente.

También han de destacarse como nombres importantes de los primeros tiempos psicoanalíticos a Emma Eckstein (1865-1924), ex-paciente de Freud y protagonista central del sueño paradigmático la inyección de Irma. Esta mujer en 1897 
trataba pacientes psicoanalíticamente, aunque nunca formó parte de las instituciones oficiales. Por otro lado está nuestra Sabina Nicolaievna Spielrein (1885-1941), miembro de la Asociación Psicoanalítica de Viena desde el 11 de octubre de 1911, justamente el mismo día que Margarethe Hilferding renunció a la membresía.

Otras mujeres pioneras del movimiento psicoanalítico fueron la doctora Tatiana Rosenthal (1885-1921), una psiquiatra rusa formada en Zúrich, que se suicidó con 36 años, que fue miembro de la Asociación de Viena desde 1911. Poco tiempo después se trasladó a su ciudad natal, San Petersburgo, trabajando a partir de 1919 bajo la dirección de Vladímir Béjterev (1857-1927) en el Instituto de Investigaciones sobre Patología Cerebral, dirigiendo la sección de neurosis y psicosis infantiles y posteriormente en una clínica para niños minusválidos. De ella partió la idea del Hogar-Laboratorio para chicos que dirigió Vera Schmidt (1889-1937).

Igualmente merecen un lugar en el recuerdo Lou Andreas-Salomé (1861-1937), que asistió a las reuniones de los miércoles desde octubre de 1912 hasta abril del siguiente año y Hermine HugHellmuth (1871-1924) que fue miembro de la Asociación Psicoanalítica de Viena desde octubre de 1913 hasta su muerte en 1924. Finalmente, en las Actas de las reuniones de los miércoles figuran referencias a otras mujeres, generalmente como invitadas, tales como la señora de Ernst Oppenheim (un profesor de lenguas clásicas y miembro de la Asociación Psicoanalítica de Viena), la cual asistió a algunas reuniones en octubre y diciembre de 1910, la mujer del doctor Stegmann (uno de los fundadores de la Asociación
Psicoanalítica de Berlín), la cual acudió a algunas sesiones en noviembre y diciembre de 1911, la señora de Hans Sachs, cuyo nombre está registrado en sesiones de 1912, 1913 y de años sucesivos, así como otras mujeres menos relevantes. Con posterioridad, ya comenzarán a ser conocidas las psicoanalistas de la segunda generación, como Erzsebet Radó-Revesz (1887-1923), Helene Deutsch (1884-1982), Beata (Tola) Rank (1896-1967), Anna Freud (1895-1982), Eugénie Sokolnicka (1884-1934), Karen Horney (1885-1952), Melanie Klein (1882-1960), Sophie Morgenstern (1875-1940), Marie Bonaparte (1882-1962) y Ruth Mack-Brunswick (1897-1946). Eran, en su mayor parte mujeres centroeuropeas que tuvieron que sufrir y tratar de superar el ambiente conservador que las empujaba hacia tres únicas funciones, esposa, madre y ama de casa, y, en algún caso, a hija destinada a cuidar a los padres en la vejez. Todas ellas deben ser estimadas no sólo como pioneras del psicoanálisis, sino también como las primeras abanderadas del feminismo constructivo $(1,2)$.

Cartas secretas en el Palacio Wilson de Ginebra: el hallazgo de una mujer olvidada

En 1977 se encontró por azar en el sótano del Palacio Wilson de Ginebra una caja con documentos personales de Sabina Spielrein, una rusa que había estado por última vez en esta ciudad suiza en 1923 ocupando un puesto como docente de psicoanálisis en el Instituto Rousseau, que tenía entonces su sede en este edificio. Cuando tuvo lugar el descubrimiento de tales documentos personales se sabía bastante poco de Sabina, a pesar de haber 
sido una de las primeras mujeres que perteneció a la Asociación Psicoanalítica de Viena. Se conocía si acaso que había sido paciente y discípula de Carl Gustav Jung y que Freud la había citado a pie de página en Más allá del principio de placer, refiriendo un trabajo suyo que consideraba como un antecedente del concepto de pulsión de muerte (3).

A mitad de la década de los setenta, tras la publicación de la Correspondencia Freud-Jung (4), se pudo ampliar lo que hasta entonces sabíamos de Sabina, pues Jung en las cartas que envió a Freud le hace varios comentarios de ella como caso clínico y como responsable de determinados conflictos personales. Todos esos datos se enriquecieron el año siguiente, tras de ver la luz el cuarto tomo de Minutes of the Viena Psychoanalytic Society (5), aunque ya en el tomo tercero consta la participación de Sabina en varias sesiones en la Asociación Psicoanalítica vienesa entre el 11 de octubre de 1911, fecha en que fue propuesta como miembro de dicho grupo profesional, hasta el 27 de marzo de 1912, que es su última asistencia registrada (6).

Sabina Spielrein era una psicoanalista de orientación junguiana, como señala Aldo Carotenuto, quien en 1977 habló de ella en Sentido y contenido de la psicología analítica (7), donde refiere la influencia que tuvo sobre algunas de las principales ideas de Jung, especialmente en los conceptos de ánima y sombra. Según refiere en otro lugar el propio Carotenuto (8), en octubre de 1977 su colega y amigo Carlo Trombetta contactó con el profesor George Morsier de Ginebra, responsable del hallazgo de la caja de documentos de Sabina en el Palacio
Wilson, los cuales remitió a Carotenuto. Basándose en este material, Carotenuto y Trombetta editaron en 1980 Diario de una secreta simetría. Sabina Spielrein entre Jung y Freud (8). Poco después se descubrieron más documentos en el archivo personal de la familia del psicólogo Edouard Claparède y en el archivo de Morsier, con cuya nueva información apareció en una reedición de la anterior obra en 1983 (9).

En 1988 Mireille Cifali nos enriquecerá el conocimiento de Sabina con un artículo titulado Una mujer en el psicoanálisis (10) y en 1990 Christine Brinkgreve, Annet Mooij y Adeline van Waning publican el artículo Hermine HugHellmuth y Sabina Spielrein: ignoradas pioneras del psicoanálisis (11) y tres años después John Kerr edita La historia secreta del psicoanálisis (12), donde se tiene en cuenta toda la documentación citada para ir dando una interesante visión de los avatares del movimiento psicoanalítico en sus primeros años, resaltando el papel que en todo ello tuvo Sabina, especialmente en las conflictivas relaciones entre Freud y Jung. En 1992 aparece en inglés Las mujeres de Freud de Lisa Appignanesi y John Forrester, donde hay un extenso capítulo dedicado a Sabina y Loë Kanh, que fue esposa de Ernst Jones y paciente de Freud (13). En 1994 Bernhard Minder da a la luz el artículo Sabina Spielrein, paciente de Jung (14) y el año siguiente se edita en francés Histoire de la psychanalyse en Russie, que había escrito en ruso Alexandre Etkind (15), donde hay un extenso capítulo dedicado a Spielrein. Por fin, en 1996, aparece en nuestro país la novela biográfica de Alnaes intitulada Sabina (16), que aportó algunas novedosas 
HISTORIA

informaciones, aunque debe subrayarse que se trata de una construcción novelada sin el rigor de los trabajos históricos. El mismo defecto suelen tener, salvo excepciones, la mayor parte de trabajos que están apareciendo en Internet.

Una rusa judía en Burghölzli: ¿una curación por amor?

Sabina Nicolaievna Spielrein (1885-1941) nació en la ciudad rusa de Róstov sobre el Don (Rusia) en 1885 (hay otras referencias que dan 1886), en el seno de una familia judía y cosmopolita que pasaba sus vacaciones en San Petersburgo, en París, en las orillas del lago Constanza de Suiza y en otros lugares de élite. Tenía cuatro hermanos menores, tres varones y una chica, Isaak (1891-1935?), Jean, Emile (que murió de tifus a los 6 años) y Emil, el primero de los cuales fue un reconocido psicólogo, que llegó a ser director en 1923 de la sección psicotécnica del Instituto de Filosofía Científica y Laboratorio de Psicotecnia Industrial del Comisariado del Pueblo en el Trabajo y en 1928 redactor de la revista Psicotécnica y Psicofisiología del Trabajo, así como presidente de la Sociedad de Psicotécnica de Rusia. En enero de 1935 fue acusado de trotskismo, siendo arrestado y posiblemente fusilado (15).

El padre de Sabina, Nikólai Spielrein, era un hombre de negocios, representante de una importante sociedad mercantil europea y que al parecer tenía un carácter colérico, por lo que con frecuencia pegaba a sus hijos. Eva, la madre, era una licenciada universitaria que ejerció como odontóloga cuando sus hijos eran pequeños. Se ha escrito que educó a Sabina, la mayor de los cinco descendientes, en la más absoluta ignorancia sexual, llegando incluso a conseguir que se modificase el contenido curricular del Gymnasium de Róstov a donde acudía Sabina, para que no tuviera que estudiar la reproducción de los organismos durante las clases de biología.

Sabina manifestó desde su infancia una imaginación desbordante, sufriendo mucho a causa de una especie de alucinación visual en la que veía dos gatos amenazantes sentados en una cómoda, lo que abocó en manifestaciones de angustia nocturna y fobias a los animales. Poco después, alrededor de los cuatro años, comenzó con una sintomatología consistente en retener sus heces, incluso durante dos semanas, tomando el hábito de sentarse sobre sus talones para impedir la defecación y conseguir así una placentera excitación sexual. A los siete años esta práctica la cambió por una masturbación genital compulsiva, manifestando también ideas obsesivas escatológicas cuando comía. Ya a los dieciocho años su estado clínico empeoró, apareciendo crisis depresivas, así como risas y gritos impulsivos, lo que hizo que sus padres la ingresaran en el hospital cantonal de Zúrich, más conocido como Burghölzli, en donde estuvo desde el 17 de agosto de 1904 hasta el 1 de junio de 1905. Con anterioridad Sabina había estado ingresada en dos clínicas privadas de Suiza, siendo tratada por el doctor Heller y el doctor Monakow respectivamente (16). Cuando ingresó en Burghölzli tenía 19 años, siendo diagnosticada por Jung de una grave histeria (aunque en su historia clínica que aún se conserva consta un primer diagnóstico de demencia precoz), iniciando con él una especie de tratamiento psicoanalítico a lo largo 
de unos tres meses, terapia cargada de sugestiones y otros ingredientes ajenos a lo que hoy entendemos por psicoanálisis. Aun con todo esto, Sabina era una chica que se había beneficiado de la apertura liberal zarista de su época, lo que le permitió realizar los estudios de bachillerato, oportunidad poco frecuente para las jóvenes de entonces, habiendo sido una alumna excelente que incluso llevó a cabo eruditos trabajos sobre historia de la religión (16).

Según consta en la historia clínica del hospital zuriqués, Sabina era una muchacha correcta y educada, aunque por su origen ruso y por su etnia judía se la consideraba como una persona exótica. En lo que toca a su psicopatología, Jung en una conferencia que dictó en Amsterdam en 1907 bajo el título La teoría freudiana de la histeria (17), comentó que la paciente había aquejado a partir de los 13 años fantasías de carácter perverso que la acosaban de forma obsesiva, como, por ejemplo, el no poder sentarse en la mesa para comer o ver a alguien alimentándose, particularmente a su padre, sin pensar en la defecación. Tampoco era capaz de mirar o tocar las manos de su progenitor sin experimentar excitación sexual, y, si le reñían por cualquier motivo, reaccionaba sacando compulsivamente la lengua o dando una fuerte carcajada. Además, inesperadamente emitía gritos de horror y gestos de asco, lo que se acompañaba de la visión de la mano castigadora de su padre combinada con excitación sexual, imágenes que abocaban en una masturbación mal disimulada. En el momento de su ingreso en el hospital, su estado clínico se caracterizaba por profundas depresiones que alternaban con accesos de risas, llantos y gritos, así como los referidos gestos de sacar la lengua cuando era tocada, dando en esos momentos la impresión de estar a punto de echarse a reír (17).

Cuando Sabina empezó a ser tratada, Jung y Riklin estaban interesados en los experimentos de asociación verbal y ambos se iniciaban en la terapia psicoanalítica, habiendo sido ella la primera paciente que Jung abordó con tal modelo de intervención a lo largo de unos tres meses $(12,13)$. En cuanto Sabina empezó a restablecerse, dados sus intereses vocacionales, se integró como ayudante voluntaria en los experimentos de Jung y Riklin, matriculándose en la licenciatura de medicina en 1905 en la Universidad de Zúrich, unos meses antes de ser dada de alta, lo que tuvo lugar el 1 de junio de ese año.

Poco a poco se fue fortaleciendo la relación personal entre Sabina y Carl Gustav, hasta llegar a ser algo más que una mera amistad, existiendo abundantes referencias a variados intercambios eróticosexuales entre ambos $(8,9)$. En enero de 1909, la mujer de Jung con el fin de tratar de dar fin a estos amores extraconyugales, escribió en forma anónima a la madre de Sabina, relatándole lo que sucedía. Ante esto, la señora Spielrein remitió una indignada carta a Jung indicándole que no debía destruir a su hija después de haberla salvado. Jung le respondió de forma cínica y fría, echándole en cara que no cobraba honorarios en los encuentros con Sabina, lo que impedía el establecimiento de los límites propios de una relación profesional. Por tales motivos, el 26 de febrero de 1909 tuvo lugar un borrascoso encuentro entre Jung y Spielrein, que acabó con un ataque 
físico de ésta a aquél con un abrecartas que estaba en el escritorio, para salir después huyendo despavorida del consultorio (12). Tras haber transcurrido algunos días Jung le escribió a Freud manifestándole entre otras cosas que su primer paciente psicoanalítico lo había traicionado, poniendo en marcha un terrible escándalo, exclusivamente por haber renunciado a darle un hijo (12). Freud, en su respuesta, no hizo referencias explícitas al tema, comentando de pasada que ser difamados era un precio a pagar en el oficio psicoanalítico, aunque no por ello había que renunciar a seguir con la tarea.

En lo que toca a Sabina, estaba indignada por el curso de los acontecimientos, como se evidencia en los borradores de las cartas que escribió en junio de 1909 (8, 9). Algo antes, el 30 de mayo, se había dirigido a Freud solicitándole una breve entrevista (12), carta que llegó el 3 de junio, remitiéndosela Freud a Jung el mismo día, a la par que le cuestionaba si sabía algo de la persona que firmaba o si tenía alguna opinión al respecto y rogándole que le pusiera un telegrama, que no ha sido encontrado. El día siguiente Freud le escribió a Sabina para que le informara sobre el motivo concreto de su demanda de cita y Jung por su parte mandó el mismo día un telegrama a Freud indicándole que quien le solicitaba la cita era la misma persona de la que ya le había escrito con anterioridad, su primer caso psicoanalítico, señalando que tenía hacia ella especial consideración y afecto (4). La contestación de Freud el 7 de junio se centró en un comentario con relación a que tales experiencias también le habían sucedido a él y que ayudaban a endurecer la piel para poder controlar la contratrans- ferencia (siendo ésta una de las primeras referencias a este concepto), poniendo la última responsabilidad de los hechos en las pacientes histéricas, señalando que estas mujeres pueden sacar a relucir, como encantos, todas las perfecciones psíquicas imaginables, hasta que han logrado su objetivo (4). En cuanto al contenido de la nueva misiva que Freud remitió a Sabina el 8 de junio de 1909, tras conocer ya el asunto con cierta profundidad, era un claro intento de justificar y proteger a Jung, recomendándole a la chica que reprimiera todas esas vivencias (8). En su respuesta del 10 de junio, Sabina le comentó a Freud que la represión no era un buen camino, pues se quedaría sin la posibilidad de amar a otro hombre, optando por enfrentarse a Jung y ponerle ciertas condiciones para dar fin al asunto, como reparar su reputación ante sus padres y ante Freud, lo que Jung llevó finalmente a cabo, lamentando la bellaquería que había cometido con la señora Spielrein y admitiendo su parte de responsabilidad en el affaire, aunque sin mencionar que hubieran tenido lugar entre ellos relaciones genuínamente sexuales. Sin embargo, en el diario personal que por entonces escribía Sabina, aparece constantemente la palabra poesía como sinónimo de los encuentros sexuales que tenía con él (12).

Discípula de Freud: una nueva teoría de la represión

A finales de agosto de 1910, transcurridos ya cinco meses del Congreso Psicoanalítico de Nuremberg, Sabina dio un paso definitivo en su vida personal y profesional: tomó la decisión de trasladarse a Viena para seguir su formación con Freud, con lo que además se alejaba de Jung. Poco antes había dado los toques 
finales a su tesis de doctorado, que dirigía Eugen Bleuler, en la que había llevado a cabo una investigación de carácter psicoanalítico sobre la demencia precoz (esquizofrenia) crónica, titulada Sobre el contenido psicológico de un caso de demencia precoz, que fue editada por el Jahrbuch en 1911 (18). Presentó este trabajo el 11 de febrero de ese año, un mes después de haber superado los exámenes finales de la licenciatura de medicina, en donde obtuvo matrícula de honor en psiquiatría, dando fin a sus estudios oficiales en el mes de junio de 1911.

La tesis consistía en el estudio clínico de una paciente esquizofrénica, hostil y deteriorada, que sólo estaba preocupada por la muerte y la decadencia, aunque era incapaz de coordinar verbalmente la mayor parte de sus pensamientos. Sabina fue descifrando pacientemente los contenidos psicológicos de sus diferentes delirios, llegando a la conclusión de que en éstos podía verse la participación de dos ingredientes antagónicos en el deseo sexual, un elemento disgregador y por tanto destructivo, y un elemento constructivo que llamó componente de transformación, algo cercano a lo que Freud bautizaría después como sublimación. En estas ideas algunos han situado la semilla de la pulsión de muerte, aunque realmente se trata de los inicios de una elegante teoría de la represión, que Spielrein desarrollaría más profundamente en un trabajo ulterior.

El miércoles 29 de noviembre de 1911, tras haber sido aceptada como miembro de la Asociación Psicoanalítica de Viena, Sabina es recibida por Freud para discutir el contenido de su tesis, en la que aquélla defendía que los conflictos fundamentales que tienen lugar en la mente humana no son el enfrentamiento entre las pulsiones del yo y las pulsiones sexuales, sino, como antes se ha insinuado, entre la vida y la muerte, de modo que la tendencia destructiva humana ha de luchar contra la misma sexualidad: el núcleo de su trabajo es que la destructividad es la última causa de la vida.

Cuando Spielrein elaboró esta teoría tenía sin duda en la mente las ideas de Élie Metchnikoff, un ruso expatriado en Francia que llegó a ser director del Instituto Pasteur de París y premio Nobel de medicina en 1907, quien en su obra $E l$ ritmo de la vida, editada en 1903, había especulado sobre la existencia en el ser humano de un deseo de morir, que se pondría en evidencia al final de una larga vida (12). Spielrein puso este deseo de muerte en relación con un aspecto destructivo de la pulsión sexual: la sexualidad sería intrínsecamente ambivalente respecto al yo, pues busca la disolución de éste para producir la vida (12). Esta teoría de Spielrein sobre la destrucción, el sacrificio y la transformación tenía también una indudable deuda con Nietzsche y Wagner.

Entendemos, en todo caso, que lo importante a destacar es que tal teoría, que cuajaría un año después, ha de estimarse como una novedosa explicación de la represión y no como una demostración de la existencia de la pulsión de muerte. Tales ideas se consolidaron tras pasar Spielrein un semestre en Múnich, donde asistió a clases de historia del arte durante la primavera de 1911, regresando a Viena en agosto: la coexistencia de la destructividad y la sexualidad en los humanos daría cuenta de por qué la represión actúa 
específicamente contra los deseos sexuales. Todo ello aparecería bien organizado en el trabajo La destrucción como causa del nacimiento que se publicará por primera vez en 1912 (19) y del que Freud dijo que no había terminado de comprender (3).

Para Spielrein, el misterio de la específica actuación de la represión sobre los deseos sexuales individuales, y no respecto a otros deseos, residía en su original concepción de la sexualidad, que superaba el enfoque freudiano, centrado en el enfrentamiento de las pulsiones sexuales con las pulsiones de autoconservación, en el placer/displacer por medio de la descarga y en la represión como una consecuencia de la naturaleza prohibida de la pulsión libidinal, fundamentalmente por el objeto hacia el que se dirige. Sin embargo, al modo de ver de Spielrein, habría una pulsión de conservación del individuo y otra de la especie, defendiendo paralelamente la existencia de dos estructuras psíquicas, el yo y el inconsciente, funcionando el yo gracias a la energía aportada por la pulsión de autoconservación, siendo su máximo objetivo mantener indemne la propia individualidad, rechazando todo aquello que pudiera imponerle un cambio no deseado. En cuanto al inconsciente, sería más bien colectivo que individual, procediendo su energía de la pulsión de conservación de la especie, esto es, de la sexualidad, persiguiendo el mantenimiento de la especie por encima del individuo, por lo que actuaría en contra del yo, por lo que éste viviría como una amenaza la presencia del deseo sexual. De aquí que el yo siempre respondiera con una actitud de represión ante la activación del deseo sexual, mostrando en la mente imágenes de destrucción y muerte, las cuales representarían las protestas de dicho yo ante la amenaza de su disolución, radicando en ello la última fuente de la represión de los deseos sexuales. No se trata exactamente, por tanto, de lo que en 1920 Freud delimitaría como pulsión de muerte, como señala en la antes referida nota a pie de página de una de sus obras (3).

El 20 y 21 de septiembre de 1911 se celebró en Weimar el III Congreso Internacional de Psicoanálisis, al que, entre otras mujeres, asistieron Lou AndreasSalomé. Al evento también iba a acudir Sabina, pero finalmente no pudo hacerlo a causa de una inflamación de un tobillo, aunque suponemos que ello no era sino una excusa, siendo la causa real el no encontrarse con Toni Wolff, la nueva discípula y el nuevo amor de Jung, el cual también iba acompañado de Emma, su mujer. Tras la celebración del citado congreso, fue cuando Sabina trató de contactar con Freud, para lo que pidió a Jung una carta de presentación, que éste no consideró necesaria, puesto que ya le había hablado de ella con anterioridad (12).

El 11 de octubre de 1911 tenía lugar la primera reunión del nuevo curso de la Asociación Psicoanalítica de Viena, que, como era costumbre en la primera sesión, se celebró en el café Arkaden. Adler y algunos de sus seguidores ya habían abandonado el grupo freudiano, aunque aún asistían, entre otros, Wilhelm Stekel y Margarethe Hilferding. Curiosamente el mismo día en que Sabina presentaba su petición para ser miembro de la Asociación Psicoanalítica de Viena, dimitía la referida Margarethe que se unió a la Sociedad para el Psicoanálisis Libre liderada por Alfred Adler desde el mes de junio anterior (6). 
Sabina fue aceptada por unanimidad, en contra de las maniobras de Isidor Sadger, que pensaba que las mujeres no debían formar parte de la Asociación, acudiendo durante todo el curso de forma regular a las reuniones de los miércoles que ya no tenían lugar en la consulta de Freud, sino en la sede del Colegio de Doctores de Viena. Según consta en los Minutes $(5,6)$, Sabina intervino por vez primera en la sesión del 8 de noviembre de 1911, dando su opinión en el debate que se abrió en relación con una comunicación presentada por Stekel y Reinhold titulada Sobre la pretendida atemporalidad del inconsciente, estando presentes Dattner, Federn, Freud, Friedjung, Heller, Hitschmann, Jekels, Nepallek, Rank, Reitler, Rosenstein, Sachs, Sadger, Steiner, Stekel y Tausk, y, como invitado, un tal Krauss (6). Sabina empezó diciendo que ella sólo podía ver las cosas según el punto de vista de su escuela, haciendo referencia a Jung, señalando el origen filogenético de los contenidos del inconsciente para justificar su atemporalidad. Federn y Tausk acogieron bien esta aportación, pero Freud atacó la tesis de la influencia filogenética, sin duda como expresión del desacuerdo con Jung, aunque comentó de forma favorable la puesta en primer plano del rasgo desconocedor del tiempo del inconsciente, dado que ello completaba el retrato del mismo como sistema.

En la reunión del 15 de noviembre de 1911, Reik presentó la comunicación titulada Sobre la muerte y sobre la sexualidad, aprovechando Spielrein el debate para presentar algunas de sus ideas sobre La destrucción como causa del nacimiento, que discutiría con más detalle en la siguiente sesión del 29 de noviembre.
Entonces se puso en marcha un confuso debate con críticas y contracríticas, manifestando el lúcido Viktor Tausk que consideraba muy valiosa la idea central de Spielrein acerca de que la represión de la sexualidad procedía de su componente destructivo, pues ello fundamentaba una nueva y más profunda teoría de la represión. Lo más sorpresivo fue la intervención de Freud, que planteó una crítica directa a la utilización por parte de Jung del material mitológico para tratar de solucionar las cuestiones psicoanalíticas, comentando también de pasada que Spielrein había tratado de fundamentar la teoría de las pulsiones con proposiciones biológicas y no psicológicas. Desde la perspectiva de Sabina aquella reunión debió ser muy decepcionante, pues no sólo había fracasado en el intento de dar a conocer sus nuevas ideas, sino que también se había percatado de que su mentor, Jung, no tenía buena acogida entre los vieneses. Y es que ella desconocía que entre Freud y Jung se estaba planteando un enfrentamiento personal, aunque encubierto en razones aparentemente teóricas, que la mujer de éste había estado tratando de evitar limando asperezas (12).

El 30 de noviembre de 1911, Freud escribió a Jung comentándole su postura en la sesión del día anterior en la Asociación Psicoanalítica de Viena, describiéndole entre otras cosas las objeciones que había puesto a Sabina, además de criticarle a él su progresivo alejamiento de la teoría libidinal. Jung, en efecto, estaba por entonces asimilando la libido a cualquier tipo de deseo a través de una concepción genética, en donde lo energético vital primaba sobre lo estrictamente sexual. Tal desexualización 
de la libido no podía ser asumida por Freud, pues rompía todo su edificio teórico.

A finales de diciembre de 1911, Sabina pasó dos semanas de vacaciones en su ciudad natal, en cuya universidad dictó una conferencia sobre psicología infantil. A su vuelta a Viena, empezó a hacerse cargo en 1912 de sus dos primeros pacientes remitidos por Freud y a los que no cobraba (13). Por entonces también redactó el ensayo Contribuciones a la comprensión del alma de un niño (20), primera muestra del interés de Spielrein por el campo de la psicología infantil.

El 27 de marzo de 1912, Tausk dio una conferencia en la Asociación Psicoanalítica de Viena con el título $L a$ sexualidad y el yo, donde había claras muestras de la aceptación de la teoría de Spielrein sobre el componente destructivo que portaba la sexualidad, estableciendo que tal elemento tendría una naturaleza sádica en el hombre y masoquista en la mujer, añadiendo que toda emoción fuerte, según ideas de Klages, tenía como propiedad un peligro de disolución para el yo. Sabina intervino manifestando que el problema del sado-masoquismo expuesto por Tausk era idéntico al de sus ideas sobre el componente destructivo de la sexualidad, lo que fue corroborado por Freud (5).

Estancia en Berlín: un casamiento de conveniencia

En torno a la tercera semana de abril de 1912, Sabina se traslada a Berlín, probablemente buscando un ambiente más favorable que el vienés para desarrollar sus ideas. Allí conocerá a Paul Scheftel, un atractivo médico judío de personalidad algo difícil, 21 años mayor que ella, con el que se casará el 14 de junio de ese año, aunque sin duda aún seguía enamorada de Jung. En el curso de este año Sabina desaparece de la correspondencia entre Freud y Jung, aunque ella siguió carteándose con ambos, constando documentalmente que la última carta que Freud le dirigió fue el 9 de febrero de 1923, en la que la anima para instalarse en Moscú, rogándole que, cuando esté allí indique su domicilio en el encabezamiento de la carta, cosa, dice Freud, que demasiadas pocas mujeres hacen.

En una carta muy anterior, fechada el 20 de agosto de 1912, Freud la había felicitado, diciéndole que ya estaba medio curada de su ligazón neurótica con Jung, aunque aún restase la otra mitad, recordándole si todavía desea combatir al tirano por medio de un análisis con él (8). Poco después, en otoño de 1912, Sabina se inscribe en la Asociación Psicoanalítica de Berlín, pero enseguida se percató de que no congeniaba con Karl Abraham, el principal líder del grupo, aunque siguió su trabajo en Alemania.

El 20 de enero de 1913, Freud le comenta a Sabina en una carta que la amistad de él con Jung se había roto definitivamente, comunicándole también que próximamente iba a salir una crítica de Paul Federn acerca de su trabajo sobre la destrucción como causa del nacimiento, recomendándole que la leyera con benevolencia. En tal reseña, Federn caricaturizó la argumentación de Spielrein, dando la impresión de que ésta lo único que intentaba probar era que la participación de la destructividad era indispensable en la sexualidad, atacando además su método de trabajo, dado que intentaba dar cuenta 
de formaciones psíquicas aparecidas tardíamente recurriendo a causas muy lejanas, ignorando los determinantes más inmediatos, lo que recordaba a la forma de actuar de los pensadores místicos, admitiendo en todo caso que su contribución era interesante (8). Leyendo esta crítica entre líneas, hay un ataque a las ideas de Jung más que a las de Spielrein.

A mediados de 1913 Sabina estaba a punto de tener su primera hija, a la que llamaría Renata, y, así mismo, su productividad intelectual era notable, como la confirma la publicación de cinco ensayos cortos: Amor materno (21), Autosatisfacción en el simbolismo del pie (22), El sueño del Padre Freudenreich (23), El soñar inconsciente en el duelo de Kuprins (24) y La suegra (25), que se editaron en Imago, en Zentralblatt y en Internationale Zeitschrift. Pero aún con ello Sabina no terminaba de encontrar su lugar en el psicoanálisis, por lo que decidió regresar a Suiza y emprender un nuevo camino al margen del mismo, comprometiéndose en tareas puramente médicas y en componer música (13). Sin embargo, por estos años redactó cinco trabajos sin mucha inspiración: El nombre olvidado (26), Simbolismo animal y fobia en un niño (27) y Dos sueños sobre la menstruación (28) en 1914; Una decisión judicial inconsciente (29) en 1915; y Las manifestaciones del complejo de Edipo en edad infantil (30) en 1916.

Una vez finalizada la guerra, Sabina reanuda sus compromisos con el psicoanálisis, editando nuevos trabajos y reintegrándose a la Asociación Psicoanalítica de Viena en 1919, año en el que publica una crítica sobre la literatura psicoanalítica rusa, Literatura rusa (31), y en el siguiente cinco artículos titulados $E l$ sentimiento del pudor en los niños (32), Sobre el problema del origen y desarrollo del lenguaje articulado (33), que había presentado en el Congreso de La Haya, abriendo una línea de investigación que sería muy productiva para Piaget, $L a$ mujer débil (34), Erotismo oral reprimido (35) y La teoría de la pequeña Renata sobre el nacimiento del hombre (36), los cuales aparecieron en la prestigiosa Internationale Zeitschrift für ärztliche Psychoanalyse.

Ginebra: una embajadora de Freud que fracasa

Tras detenerse unos días en Zúrich para saludar a Bleuler y a Jung, Sabina viajó a Mónaco y luego a Lausana, donde entró a trabajar como médico en una clínica quirúrgica, dejando prácticamente de lado el psicoanálisis. Incluso, tras un sueño en el que se veía como artista, se dirigió al conservatorio de la ciudad para formarse en música. Tenía entonces 35 años y su hija 7 y no acababa de centrarse profesionalmente. En otoño de 1920, resurge en la documentación psicoanalítica con ocasión del VI Congreso Internacional de Psicoanálisis celebrado en La Haya desde el 8 al 11 de septiembre, donde presenta la comunicación antes referida Sobre el problema del origen y desarrollo del lenguaje articulado (33), que reaparecerá en 1922 con el título El origen de las palabras infantiles papá y mamá (37), significando un acercamiento del psicoanálisis a la psicología académica. Aquí plantea Spielrein que las primeras palabras que pronuncia un niño, papá y mamá, están impregnadas de una cualidad mágica y del cumplimiento del deseo de 
mamar, siendo la expresión de la actuación del principio de placer, último origen de las manifestaciones comunicativas del ser humano. Este trabajo sería citado por Piaget incluso antes de ser publicado.

Tras el Congreso de La Haya, Sabina se estableció en Ginebra, siendo nombrada profesora de psicoanálisis en el Instituto Rousseau, que había nacido de una fundación previa de carácter pedagógico creada en 1912 por Edouard Claparède, un sobrino de Théodore Flournoy, a la que estaban adscritos Pierre Bovet, Raymond de Saussure, Gustav Bally, Charles Odier y Jean Piaget, a los que Spielrein analizaría. El análisis didáctico del último de ellos se extendería durante ocho meses del año 1921, con sesiones diarias, siendo interrumpido porque a Piaget no le resultaba grata la experiencia de la transferencia (12), dado que se reeditaban asuntos relacionados con su excéntrica madre (13), habiendo afirmado en 1978 que Sabina le dijo que era impermeable a la teoría psicoanalítica, aunque él admitió que le había resultado extraordinario descubrir todos sus complejos (13). Alrededor del tiempo de dar fin a su análisis y ser nombrado director del Instituto Rousseau, presentó en el VII Congreso Psicoanalítico de La Haya, en 1922, la comunicación titulada $E l$ pensamiento simbólico y el pensamiento del niño, tema seguramente inspirado en las conversaciones que tuvo con Sabina. Años después, en La concepción infantil del mundo, se ilustraría con parte del contenido del artículo de Spielrein sobre su hija Renata (13).

Spielrein acudió a Ginebra por recomendación y financiación del Comité secreto reunido en La Haya, con el fin de que ejerciera de analista didacta y de supervisora de los miembros del Instituto Rousseau interesados por el psicoanálisis, es decir, como una especie de embajadora de Freud. Pero lo cierto es que no terminó de triunfar, habiendo criticado Bovet (38) el papel que Spielrein hizo en Ginebra, calificándola de misionera y señalando que no consiguió hacer progresar el psicoanálisis tal como se proponía. A pesar de esta negativa opinión de Bovet, Sabina fue intelectualmente productiva, pues entre 1921 y 1923 redactó once artículos, uno de ellos en colaboración con Piaget titulado Algunas analogías entre el pensamiento del niño y el del afásico y el pensamiento subconsciente (39), en el que se trataba de mostrar que las tres formas de pensamiento son formas rudimentarias de un pensamiento adaptativo al entorno y no meros productos autísticos. Los restantes títulos fueron Análisis inmediato de una fobia infantil (40), El sueño de los timbres postales (41), el anteriormente citado El origen de las palabras infantiles papá y mamá (37), Suiza (42), Sueños y visiones de las estrellas fugaces (43), Las tres preguntas (44), El automóvil, símbolo de la potencia masculina (45), Un nuevo tipo de voyeur (46), Algunas breves consideraciones de la vida infantil (47) y El tiempo de la vida psíquica subliminal (48).

En todo caso, es cierto que Sabina no fue bien acogida en Ginebra, por lo que decidió abandonar esta ciudad para dirigirse a Berlín y tantear si podía asentarse aquí, tomando parte del VII Congreso Internacional de Psicoanálisis que se celebró en esta ciudad en septiembre de 1922, donde presentó la comunicación antes citada El tiempo de la vida psíquica subliminal (48), en el que argumentaba 
que los pensamientos en desarrollo de los niños y la estructura de los sueños muestran instrumentos similares para representar el tiempo, como el futuro por medio de la acción repetida, el pasado por medio de metáforas especiales que indican lejanía del presente, etc. (13).

\section{Retorno a sus orígenes y oscuro final}

Freud dudaba si Sabina debía instalarse en Berlín o trasladarse a Moscú. Finalmente le recomendó esta ciudad, donde el Instituto Psicoanalítico estaba en un buen momento bajo la dirección de Moshe Wulff, contando entre sus miembros a Lev Vygotski y Alexander R. Luria, que actuaba como secretario. Cuando Sabina partió hacia Rusia llevaba en su bolso una carta de presentación de Freud y muchos libros. Su prestigio era indudable y ello le facilitó la integración en el grupo psicoanalítico moscovita, siendo nombrada inmediatamente miembro de la Asociación Psicoanalítica de Moscú, empezando a trabajar en el campo infantil donde las mujeres tenían mayor aceptación social y actuando también como docente en el Instituto adscrito a aquella Asociación. Estos años de gloria se tornarían un infierno cuando el régimen soviético dejó de ser proclive al freudismo, de lo que se percataron Vygotski y Luria que abandonaron el psicoanálisis antes de que se establecieran las purgas estalinistas y la prohibición explícita del psicoanálisis que fue tachado de ciencia burguesa, lo que aconteció en 1936, antes de lo cual había sido clausurada en noviembre de 1929 la Asociación Psicoanalítica de Moscú. Previamente a todo ello, Sabina traducirá al ruso Más allá del principio de placer (3) con un extenso prólogo de Vygotski y Luria y dos años después vería la luz en Imago su último trabajo conocido, Dibujos infantiles con los ojos cerrados $y$ abiertos (49).

A partir de tales fechas la historia de Sabina se cubre de nubarrones, hasta el punto de no poder precisarse la fecha de nacimiento de su segunda hija, Eva, que Kerr sitúa en 1919, Alnaes en torno a 1924 y Etkind en 1926, año que parece el más razonable. Se conoce, de todos modos, que en 1923 Sabina se había instalado en Moscú y un año o año y medio después en Róstov, su ciudad natal, donde trabajó como paidóloga en una escuela, aunque, tras la prohibición de esta actividad por el Comisariado del Pueblo en 1936, actuó como médico escolar a medio tiempo (15).

Trascurridas unas décadas de silencio y gracias a la apertura política que se dio en Rusia en 1989, hemos sabido que Sabina y sus hijas fueron fusiladas en Róstov por soldados de la Wermacht a las órdenes del capitán Fritz Neumann delante de una sinagoga, y no por miembros de las SS de la Gestapo, según unos el 25 de noviembre de $1941(13,50)$, y, según otros, el 22 de julio de 1942, cuando los nazis volvieron a conquistar Róstov, situándose en este caso la muerte en el barranco del Madero de la Serpiente (15, 51), inclinándonos nosotros por aceptar la primera versión.

El marido de Sabina, Paul (Pável) Scheftel, había fallecido en 1937 de una trombosis cerebral o de un infarto cardíaco, el mismo año en que murió Nikólai Spielrein en el Gulag. Diez años antes, Pável había abandonado a su esposa, existiendo el rumor de que regresó a mitad de la década de los veinte con una hija de 
HISTORIA

otra mujer, que Sabina crio como propia tras la muerte de su esposo, rumor que Etkind ha confirmado en parte, en el sentido de verificar que tal hija existió y se llamaba Nina, habiendo huido de la masacre junto a su verdadera madre, pero sin que hubiese vivido en ningún momento con Sabina, aunque Nina ha contado que ésta y su madre habían llegado al acuerdo de hacerse cargo de
Eva y de ella si le ocurría algo a una de las dos (15).

En resumen, Sabina fue una mujer notable, que aportó ideas muy valiosas a la teoría freudiana y a la teoría lingüística, habiendo tenido una existencia conflictiva y finalmente trágica, mereciendo en todo caso un recuerdo respetuoso por sus interesantes aportaciones al psicoanálisis.

\section{BIBLIOGRAFÍA}

(1) Sánchez-Barranco, A. Las pioneras del psicoanálisis. Sevilla: Repiso Libros. 1999

(2) Sayers, J. Les mères de la psychanalyse. Paris: PUF, 1995.

(3) Freud, S. Más allá del principio de placer. Obras Completas, XVII. Buenos Aires: Amorrortu, 1979, 3-62.

(4) Freud, S. y Jung, C. G. Correspondencia. Madrid: Taurus, 1978.

(5) Numberg, H. y Federn, E. Les premiers psychanalystes. Minutes de la Société Psychanalytique de Vienne, IV. Paris: Gallimard, 1983.

(6) Nunberg, H. y Federn, E. Les premiers psychanalystes. Minutes de la Société Psychanalytique de Vienne, III. Paris: Gallimard, 1979.

(7) Carotenuto, A. Censo e contenuto della psicologia analitica. Turin: Boringhieri. 1977

(8) Carotenuto, A. y Trombetta, C. Sabina Spielrein entre Freud y Jung. Paris: Aubier Montaigne, 1981.

(9) Carotenuto, A. y Trombetta, C. A Secret Symmetry: Sabina Spielrein between Freud and Jung, ed. rev. New York: Pantheon. 1983

(10) Cifali, M. Une femme dans la psychanalyse. Sabina Spielrein, un autre portrait. Le Bloc-Notes de la Psycnanalyse, 8, 253-265. 1988

(11) Brinkgreve, C., Annet Mooij, A. y Adeline van Waning, A. Hermine Hug-Hellmuth y Sabina Spielrein: ignoradas pioneras del psicoanálisis. Zeitschrift für psychoanalytisches. Theorie und Praxis, 1990. 5, 4.

(12) Kerr, J. La historia secreta del psicoanálisis. Barcelona: Crítica, 1995.

(13) Appignanesi, L. y Forrester, J. Las mujeres de Freud. Madrid: Planeta, 1995.

(14) Minder, B. Sabina Spielrein, Jungs Patient. Zeitschrift zur Geschichte der Psychoanalyse, 1994. 7, 55-127.

(15) Etkind, A. Histoire de la psychanalyse en Russie. Paris: PUF, 1995.

(16) Alnaes, K. Sabina. Madrid: Siruela, 1996.

(17) Jung, C. G. The Freudian Theory of Hysteria. The Collected Works, 4. Princeton: Princeton University Press, 1953-1980.

(18) Spielrein, S. Über den Psychologischen Inhalt eines Falles von Schizophrenie (Dementia Praecox). Jahrbuch für psychanalytische und psychopathologische Forschungen, 1911. 3, 329-400. 
HISTORIA

(19) Spielrein, S. Die Destruktion als Ursache des Wendens. Jahrbuch für psychanalytische und psychopathologische Forschungen, 1912. 4, 465-503.

(20) Spielrein, S. Beiträge zur Kenntnis der Kindlichen Selle. Zentralblatt für Psychanalyse und Psychotherapie, 1912. 3, 57-72.

(21). Spielrein, S. Mutterliebe. Imago, 1913. 2, 253-254.

(22) Spielrein, S. Selbsfriedigung in Fussymbolik. Zentralblatt für Psychanalyse und Psychotherapie, 1913. 3, 263.

(23) Spielrein, S. Traum vom Vater Freudreich. Internationale Zeitschrift für ärztliche Psychanalyse, 1, 1913. 484-486.

(24) Spielrein, S. Das unbewusste Träumen in Kuprins Zweikempf. Imago, 1913. 2, 524-525.

(25) Spielrein, S. Die Schwiegermutter. Imago, 1913. 2, 589-591.

(26) Spielrein, S. Der vergessene Name. Internationale Zeitschrift für ärztliche Psychanalyse, 1914. 2, 383-384.

(27) Spielrein, S. Tyersymbolik und Phobie ber einem Knaben. Internationale Zeitschrift für ärztliche Psychanalyse, 1914. 2, 375-377.

(28) Spielrein, S. Zwei Mensesträume. Internationale Zeitschrift für ärztliche Psychanalyse, 1914. 2, 32-34.

(29) Spielrein, S. Ein unbewusster Richterspruch. Internationale Zeitschrift für ärztliche Psychanalyse, 1915. 3, 350.

(30) Spielrein, S. Die Äussenrungen des Oedipouskomplexes im Kindesalter. Internationale Zeitschrift für ärztliche Psychanalyse, 1916. 1, 44-48.

(31) Spielrein, S. Russische Literatur. En Berich über die Fortschritte des Psychoanalyse 1914-1919. Vienna: Internationale Psychoanalytischer Verlag, 1921.

(32) Spielrein, S. Das Schamgefühl bei Kindern. Internationale Zeitschrift für ärztliche Psychanalyse, 1920. 6, 157-158.

(33) Spielrein, S. Zur Frage der Entwicklung der Lautsprache. Internationale Zeitschrift für ärztliche Psychanalyse, 1920. 6, 401.

(34) Spielrein, S. Das Schwache Weib. Internationale Zeitschrift für ärztliche Psychanalyse, 1920. 6, 158.

(35) Spielrein, S. Verdrangte Mundoerotik. Internationale Zeitschrift für ärztliche Psychanalyse, 1920. 6, 361-362.

(36) Spielrein, S. Renatchens Menschenentschungstheorie. Internationale Zeitschrift für ärztliche Psychanalyse, 1920. 6, 155-157.

(37) Die Entstehung der kindlichen Worte Papa und Mama. Imago, 8, 345-367.

(38) Bovet, P. (1932). Vingt ans de vie de l'Institute Rousseau. Génève: Université de Genève.

(39) Spielrein, S. y Piaget, J. Quelques analogies entre la pensée de l'enfant, celle de l'aphasique et la pensée subconsciente. Archives de Psychologie, 1923. 18, 306-322.

(40) Spielrein, S. Schnellanalyse einer kindlichen Phobie. Internationale Zeitschrift für ärztliche Psychanalyse, 1921. 7, 473-474.

(41) Spielrein, S. Briefmarkentraum. Internationale Zeitschrift für ärztliche Psychanalyse, 1922. 8, 342-343.

(42) Spielrein, S. Scheweiz. Internationale Zeitschrift für ärztliche Psychanalyse, 1922. 8, 234-235.

(43) Spielrein, S. Rêve et vision des étoiles filantes. International Journal of Psycho-Analysis, 1923. 4, 129-132.

(44) Spielrein, S. Die drei Fragen. Imago, 1923. 9, 260-263.

(45) Spielrein, S. L'automobile symbole de la puissance mâle. International Journal of Psycho-Analysis, 1923. 4, 128. 
(46) Spielrein, S. Ein Zuschauertypus. Internationale Zeitschrift für ärztliche Psychanalyse, 1923. 9, 210-211.

(47) Spielrein, S. Einige kleine Mitteilungen aus dem Kinderleben. Zeitschrift für Psychanalystische Pädagogik, 1923. 2, 95-99.

(48) Spielrein, S. Die Zeit im unterschwellingen Seelenleben. Imago, 9, 1923. 300-317.

(49) Spielrein, S. Kinderzeichnungen bei offenen und geschlossenen Augen. Imago, 1931. 16, 259-291.

(50) Volnovich, J. C. Sabina Spielrein: expropiación intelectual en la historia del Psicoanálisis. 2002. Foros Temáticos: hhtp:// psicomundo.com/foros/ genero/ sabina.htm, 13 páginas.

(51) Roudinesco, É y Plon, M. Dictionnaire de la psychanalyse. Paris: Fayard. 1997

*Facultad de Psicología de la Universidad de Sevilla, Departamento de Psicología Evolutiva y de la Educación. C/. Camilo José Cela, s/n - 41018-SEVILLA

Fecha de recepción: $30-10-02$ 